\section{Uso de glucocorticoides en enfermedades alérgicas}

\section{Glucocorticoid use in allergic diseases}

Rodríguez-González M, ${ }^{1}$ Espinosa-Rosales $\mathrm{F}^{2}$

\section{INTRODUCCIÓN}

Los glucocorticoides son análogos sintéticos de las hormonas adrenocorticales, de uso común, de gran utilidad en la práctica clínica del pediatra y se consideran la piedra angular del tratamiento farmacológico de enfermedades alérgicas.

Las enfermedades alérgicas se caracterizan por signos o síntomas posteriores a la exposición con un alérgeno. Existen mecanismos inmunológicos específicos que intervienen en esta reacción de hipersensibilidad frente al alérgeno: pueden ser mediadas por inmunoglobulina $\mathrm{E}$ (IgE) o mediadas por una respuesta celular. La sensibilización precede la alergia mediada por IgE. (Figura 1). El efecto de que se active la respuesta inmunológica específica frente a un alérgeno genera inflamación tisular importante que se traduce a signos y síntomas de alergia. Cuando estas respuestas se vuelven recurrentes, ya sea por exposición continua o frecuente, y no son apropiadamente tratadas, resultan en exacerbaciones clínicas y a largo plazo en remodelación de los tejidos con compromiso en su función.

El espectro clínico de las enfermedades alérgicas es muy amplio, las más frecuentes en la población pediátrica son: rinoconjuntivitis alérgica, asma alérgica, dermatitis atópica y alergia alimentaria.

Las enfermedades alérgicas son enfermedades inflamatorias y crónicas cuya prevalencia ha incrementado en los últimos años. Estudios epidemiológicos en nuestro país han estimado que la prevalencia de las enfermedades alérgicas en población pediátrica va en incremento. Debido a que las enfermedades alérgicas
${ }^{1}$ Residente quinto año alergia e inmunología clínica pediátrica.

2Jefe de la unidad de inmunología clínica y alergia.

Instituto Nacional de Pediatría, México.

Recibido: 16 de noviembre del 2016

Aceptado: 22 de noviembre del 2016

Correspondencia

Mónica Rodríguez González

mon.medley@gmail.com

Este artículo debe citarse como

Rodríguez-González M, Espinosa-Rosales F. Uso de glucocorticoides en enfermedades alérgicas. Acta Pediatr Mex. 2017;38(1):63-71. 


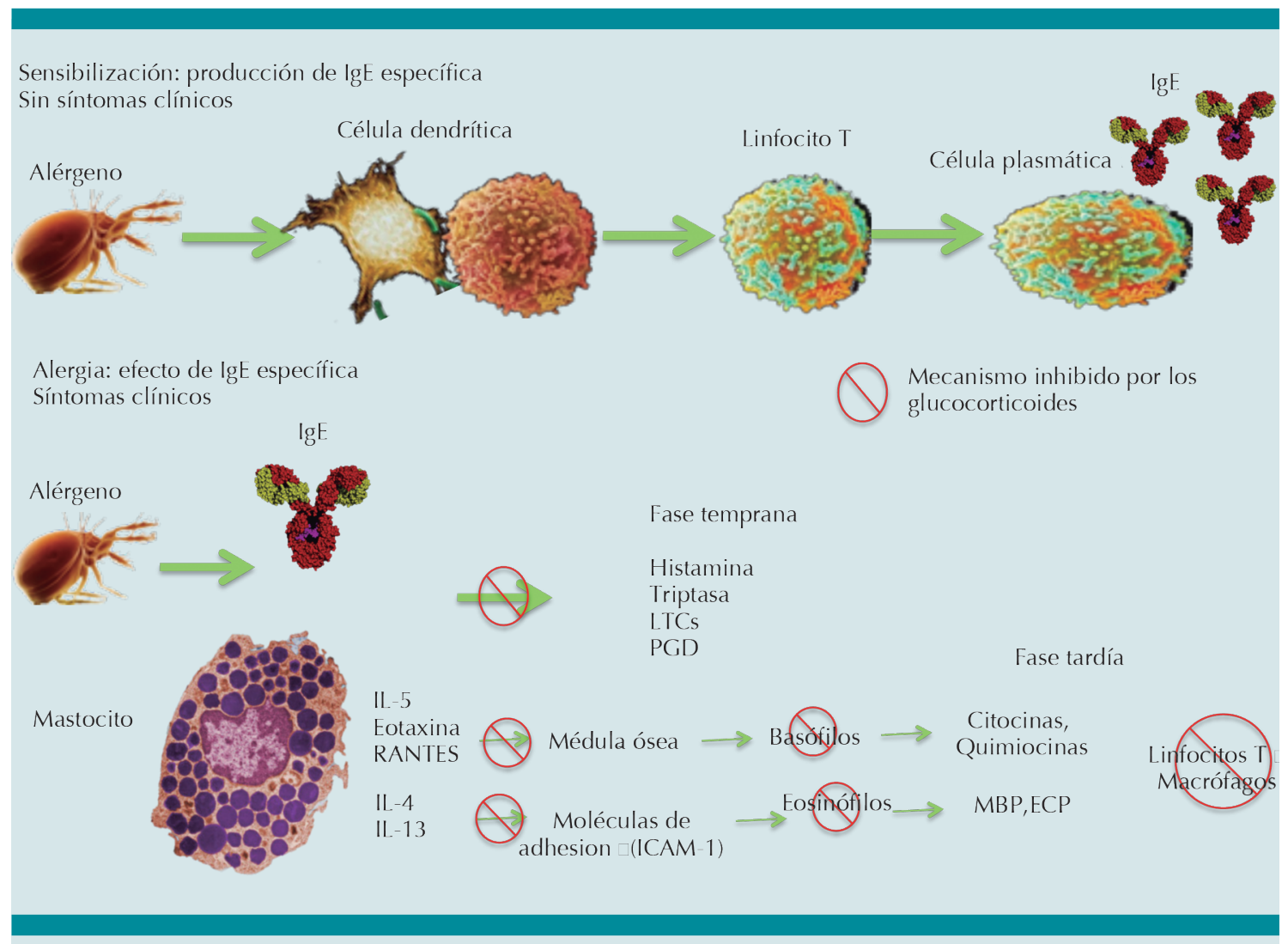

Figura 1. Mecanismo de sensibilización e inflamación alérgica mediada por IgE. Se muestran los mecanismos donde los esteroides interfieren con la inflamación y daño en alergia.

impactan negativamente en la calidad de vida, disminuyen la funcionalidad (como absentismo escolar y/o laboral), e incrementan la morbilidad y mortalidad de los sujetos afectados representan un problema de salud pública.

\section{Tratamiento de enfermedades alérgicas}

Los objetivos principales del tratamiento de las enfermedades alérgicas son prevenir o disminuir el proceso inflamatorio alérgico para aliviar los síntomas (Figura 2); para lograrlos, los pediatras contamos con 2 herramientas muy importantes:

1) la educación al paciente y sus cuidadores.

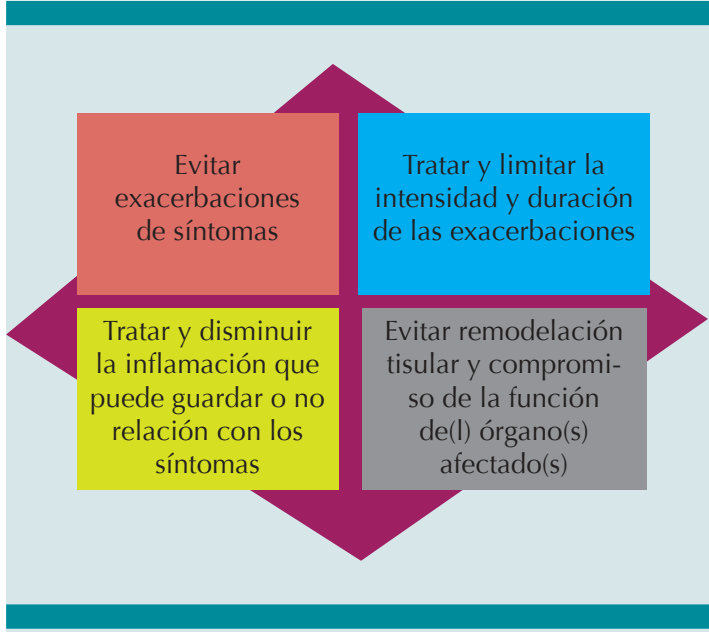

Figura 2. Objetivos principales en el tratamiento de las enfermedades alérgica. 
2) tratamiento farmacológico: como se presentó previamente, los mecanismos fisiopatológicos de una respuesta alérgica involucran distintos mediadores químicos que finalmente resultan en inflamación.

En las distintas guías disponibles para el tratamiento de las enfermedades alérgicas, los medicamentos recomendados involucran elementos que inhiben o bloquean la acción de dichos mediadores: antihistamínicos, estabilizadores de mastocitos y basófilos, antagonista de receptores de leucotrienos, broncodilatadores, anti-colinérgicos. Por otro lado, los glucocorticoides son fundamentales para el tratamiento de las enfermedades alérgicas, debido a que son los anti-inflamatorios más eficaces, disminuyen los síntomas agudos, así como la frecuencia de exacerbaciones.

El tratamiento farmacológico tiene un efecto rápido, permite disminuir los síntomas de alergia, mejora la calidad de vida y es costo-efectivo. Las enfermedades alérgicas tienen tratamientos de control y de exacerbaciones.

\section{Uso de glucocorticoides}

El uso de glucocorticoides (GC) en las enfermedades alérgicas busca atenuar la respuesta inflamatoria alérgica (mediada por IgE y celular). Lo anterior, se logra mediante la activación de su receptor citoplasmático y la subsecuente trans-represión de genes pro-inflamatorios y trans-activación de genes anti-inflamatorios; dicho efecto tarda de horas a días, pero es de gran utilidad para el tratamiento de las distintas enfermedades alérgicas.

Existen glucocorticoides para uso sistémico y local. La posibilidad de administrar glucocorticoide local (directamente en la mucosa o epitelio del órgano afectado vía inhalada, nasal, dérmica, gastrointestinal) optimiza la acción directa y disminuye los efectos secundarios sistémicos.
Debido a la cronicidad de las enfermedades alérgicas, el tratamiento con glucocorticoides suele ser por periodos prolongados. De forma general, las diferentes guías de manejo recomiendan la administración del glucocorticoide local por tiempos prolongados y con ajustes de dosis de manera escalonada. (Figura 3) En caso de cuadros graves o exacerbaciones se justifica la administración de glucocorticoides sistémicos en ciclos cortos de 3 a 10 días y en dosis anti-inflamatoria de 0.5 hasta $2 \mathrm{mg} / \mathrm{kg} / \mathrm{día}$ de prednisona/prednisolona. Esta dosis logra la disminución o remisión de síntomas alérgicos sin suprimir el eje hipotálamo-adenohipofisiario, lo que se permite la suspensión de forma súbita.

\section{Glucocorticoides inhalado}

El asma es una enfermedad inflamatoria crónica de la vía aérea, caracterizada por episodios recurrentes de obstrucción reversible del flujo aéreo. Se manifiesta con síntomas respiratorios (sibilancias, disnea, sensación de opresión torácica y/o tos) y se clasifica de acuerdo al grado de control de los síntomas que se logran con el tratamiento (no controlada, parcialmente controlada

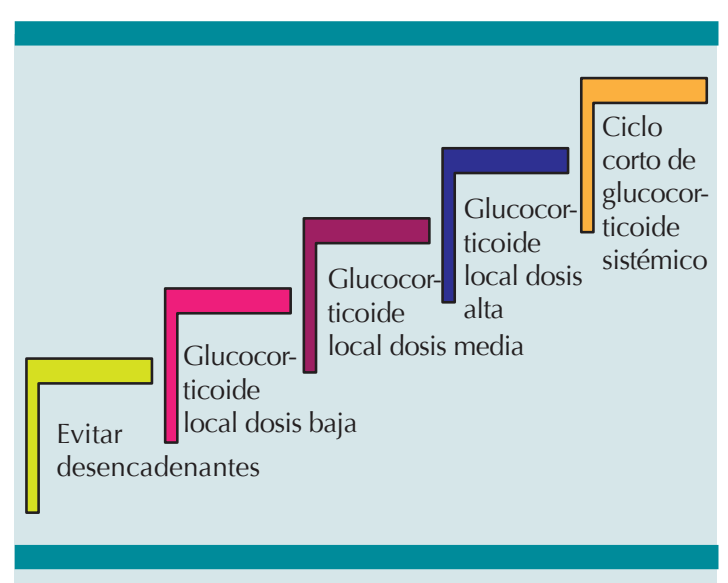

Figura 3. Se demuestra de manera general el uso escalonado del glucocorticoide local. Las dosis se inician y se ajustan dependiendo del cuadro clínico, en caso de necesitarse, puede estar indicado un esquema corto de tratamiento con glucocorticoide sistémico. 
y controlada). Siguiendo las guías de tratamiento el pediatra deberá tratar las exacerbaciones y dejar un tratamiento de control, que permita al paciente mantenerse libre de síntomas por tiempo prolongado. Debido a que el principal sustrato fisiopatológico de la enfermedad es la inflamación, los glucocorticoides inhalados son el medicamento base del tratamiento del asma no controlada y parcialmente controlada.

Los glucocorticoides son seguros y eficaces y pueden administrarse de manera local como aerosol de dosis medida, polvo seco o micronebulizaciones. Dependiendo la edad y la situación clínica el pediatra preferirá uno u otro.

\section{Cuadro 1.}

Las formulaciones químicas y la vía de administración inhalada permiten un efecto anti-inflamatorio directo en el epitelio respiratorio y la mínima o nula absorción sistémica del medicamento. Para asegurar la entrega del medicamento y no comprometer la eficacia del tratamiento es importante enseñar al paciente $y / 0$ sus cuidadores la correcta técnica de administración. (Figura 4). El aseo bucal posterior a su uso disminuye la absorción y los efectos adversos locales en la cavidad orofaríngea (candidiasis oral, disfonía). La dosis óptima depende de la gravedad y de la edad y debe ajustarse hasta lograr un adecuado control de la sintomatología. Cuadro 2.

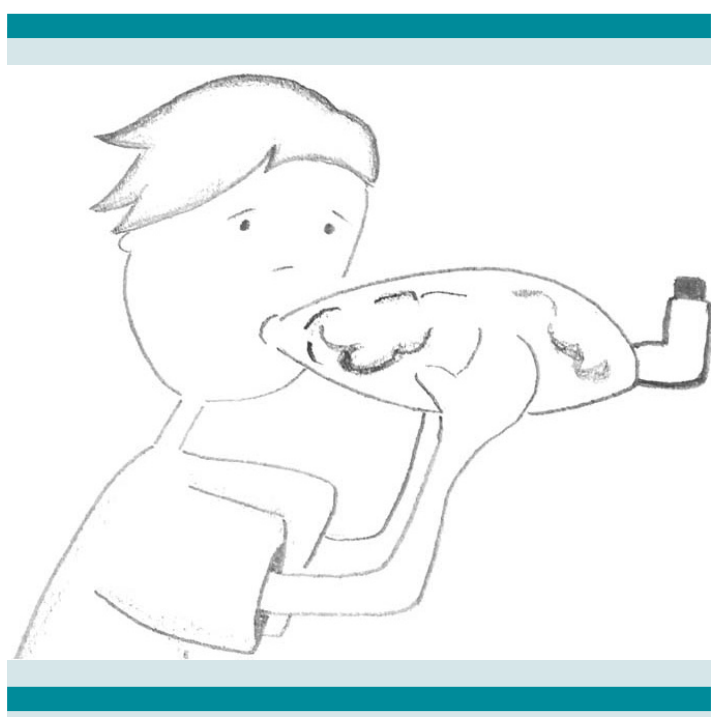

Figura 4. Técnica recomendada para administración de glucocorticoides inhalados con aerosol de dosis medida: 1) Agitar el aerosol al menos 1 minuto. 2) Colocar los labios alrededor de la aerocámara. 3) Colocar el inhalador en el otro extremo de la aerocámara. 4) Presionar el aerosol para liberar una dosis. 5) Respirar normalmente durante al menos 1 minuto por disparo. 6) Enjuagar la boca con agua.

\section{Glucocorticoides nasales}

La rinitis alérgica es la inflamación crónica de la mucosa nasal desencadenada por alérgenos en un paciente previamente sensibilizado. Se caracteriza principalmente por síntomas como obstrucción, rinorrea, estornudos y prurito. Se

Cuadro 1. Se presentan algunas características de los distintos dispositivos para administración de medicamento inhalado

\begin{tabular}{|c|c|c|c|}
\hline $\begin{array}{l}\text { Dispositivo de } \\
\text { administración }\end{array}$ & Ventajas & Desventajas & Grupo etario \\
\hline Micronebulizaciones & $\begin{array}{l}\text { Fácil administración. No } \\
\text { requiere pausa respiratoria para } \\
\text { mejorar eficacia }\end{array}$ & $\begin{array}{l}\text { Necesita equipo incluyendo mas- } \\
\text { carillas y oxígeno o nebulizador, } \\
\text { fuente de energía }\end{array}$ & $\begin{array}{l}\text { Cualquier edad. Útiles } \\
\text { en lactantes y preesco- } \\
\text { lares }\end{array}$ \\
\hline Aerosol dosis medida & Portátiles & $\begin{array}{l}\text { Necesita espaciador (recomen- } \\
\text { dado para disminuir impactación } \\
\text { orofaríngea) }\end{array}$ & Preescolares y escolares \\
\hline Polvo seco & $\begin{array}{l}\text { Portátiles. } \\
\text { Uso fácil. } \\
\text { No utiliza propelentes }\end{array}$ & $\begin{array}{l}\text { Amerita coordinación con inspi- } \\
\text { ración. } \\
\text { Dependiente de flujo inspiratorio } \\
\text { del paciente }\end{array}$ & Escolares o adolescentes \\
\hline
\end{tabular}


Rodríguez-González M y Espinosa-Rosales F. Uso de glucocorticoides en alergia

Cuadro 2a. Glucocorticoides inhalados en adolescentes (>12 años) y adultos

\begin{tabular}{|l|c|c|c|c|}
\hline Sustancia activa & Presentación & Dosis baja & Dosis media & Dosis alta \\
\hline Beclometasona & 50,100 y $250 \mathrm{mcg} /$ dosis & $100-200$ & $200-400$ & $>400$ \\
\hline Fluticasona & 50 y $250 \mathrm{mcg} / \mathrm{dosis}$ & $100-250$ & $250-500$ & $>500$ \\
\hline Mometasona & 100 y $200 \mathrm{mcg} /$ dosis & $110-220$ & $220-440$ & $>440$ \\
Budesonida & 80,100 y $160 \mathrm{mcg} /$ dosis & $200-400$ & $400-800$ & $>800$ \\
\hline Ciclesonida & 100 y $200 \mathrm{mcg} /$ dosis & 80 & $80-320$ & $>320$
\end{tabular}

Cuadro 2b. Glucocorticoides inhalados en niños (6-11 años)

\begin{tabular}{|c|c|c|c|c|}
\hline Sustancia activa & Presentación & Dosis baja & Dosis media & Dosis alta \\
\hline Beclometasona & 50,100 y $250 \mathrm{mcg} /$ dosis & $100-200$ & $200-400$ & $>400$ \\
\hline Fluticasona & 50 y 250 mcg/dosis & $100-200$ & $200-400$ & $>400$ \\
\hline Mometasona & 100 y 200 mcg/dosis & 100 & $100-400$ & $>400$ \\
\hline Budesonida & 80,100 y $160 \mathrm{mcg} /$ dosis & $100-200$ & $200-400$ & $>400$ \\
\hline Ciclesonida & 100 y 200 mcg/dosis & 80 & $80-160$ & $>160$ \\
\hline
\end{tabular}

clasifica de acuerdo a la frecuencia (persistente o intermitente) y a la intensidad de los síntomas (leve, moderada, grave). Los glucocorticoides nasales se consideran los fármacos más eficaces para disminuir síntomas nasales y, en ocasiones, también se mejoran los síntomas oculares, así mismo, han demostrado un alto perfil de seguridad en niños. Al igual que los dispositivos de inhalación utilizados en asma, una técnica adecuada de administración disminuye los efectos adversos locales: irritación nasal, epistaxis, costras nasales y raramente perforación del tabique nasal (Cuadro 3, Figura 5).

\section{Glucocorticoides tópicos en piel}

La dermatitis atópica es una enfermedad inflamatoria y crónica de la piel que ocasiona una falla en la barrera epidérmica, permitiendo la exposición constante de sustancias (alérgenos y microorganismos) que generarán una mayor respuesta inflamatoria. La lesión elemental es el eccema acompañado de prurito con una distribución característica de acuerdo a la edad: lactantes (mejillas, frente, pliegues), preescolares y escolares (superficies flexoras, peribucal, periorbitario), adolescentes (superficies extensoras, dorso de manos y pies). Se clasifica de acuerdo a intensidad de síntomas (leve, moderada y grave).

Al igual que el asma y la rinoconjuntivitis alérgica, la dermatitis atópica puede afectar considerablemente la calidad de vida, cantidad y calidad de sueño, así como la funcionalidad de los sujetos afectados. El manejo inicia con hidratación y lubricación constante con el objetivo de mejorar la función de barrera de la piel y disminuir los desencadenantes inflamatorios. $\mathrm{Si}$ los síntomas persisten y/o son graves, los glucocorticoides tópicos son muy efectivos.

Existen presentaciones en diferentes vehículos: cremas (son las más utilizados, cómodas y muy bien toleradas, con base agua y aceite), ungüentos (base grasosa que permite mayor absorción en piel muy seca o engrosada) y lociones/sprays (útiles para zonas de piel cabelluda). Si se aplican 
Cuadro 3. Glucocorticoides nasales

\begin{tabular}{|c|c|c|}
\hline Sustancia activa & Presentación & Dosis \\
\hline Furoato de Mometasona & $50 \mathrm{mcg} /$ dosis & $\begin{array}{l}>2 \text { años: } 1 \text { disparo } \mathrm{c} / 24 \mathrm{hrs} \\
>12 \text { años: } 1-2 \text { disparos } \mathrm{c} / 24 \mathrm{hrs}\end{array}$ \\
\hline Furoato de Fluticasona & $27.5 \mathrm{mcg} / \mathrm{dosis}$ & $\begin{array}{l}>2 \text { años: } 1 \text { disparo } \mathrm{c} / 24 \mathrm{hrs} \\
>12 \text { años: } 1-2 \text { disparos } \mathrm{c} / 24 \mathrm{hrs}\end{array}$ \\
\hline Propionato de Fluticasona & $50 \mathrm{mcg} /$ dosis & $\begin{array}{l}>4 \text { años: } 1 \text { disparo c/24 hrs } \\
>12 \text { años: } 1-2 \text { disparos c/24 hrs }\end{array}$ \\
\hline Budesonida & 32 y $64 \mathrm{mcg} /$ dosis & $\begin{array}{l}>6 \text { años: } 1-2 \text { disparos } \mathrm{c} / 24 \mathrm{hrs} \\
>12 \text { años: } 1-4 \text { disparos } \mathrm{c} / 24 \mathrm{hrs}\end{array}$ \\
\hline Ciclesonida & $50 \mathrm{mcg} /$ dosis & $\begin{array}{l}>6 \text { años: } 1-2 \text { disparos c/24 hrs } \\
>12 \text { años: } 1-4 \text { disparos c/12 hrs }\end{array}$ \\
\hline Triamcinolona & $55 \mathrm{mcg} /$ dosis & $>6$ años: $1-2$ disparos c/24 hrs \\
\hline Dipropionato de Beclometasona & $42 \mathrm{mcg} / \mathrm{dosis}$ & $>6$ años: $1-2$ disparos c/12 hrs \\
\hline
\end{tabular}

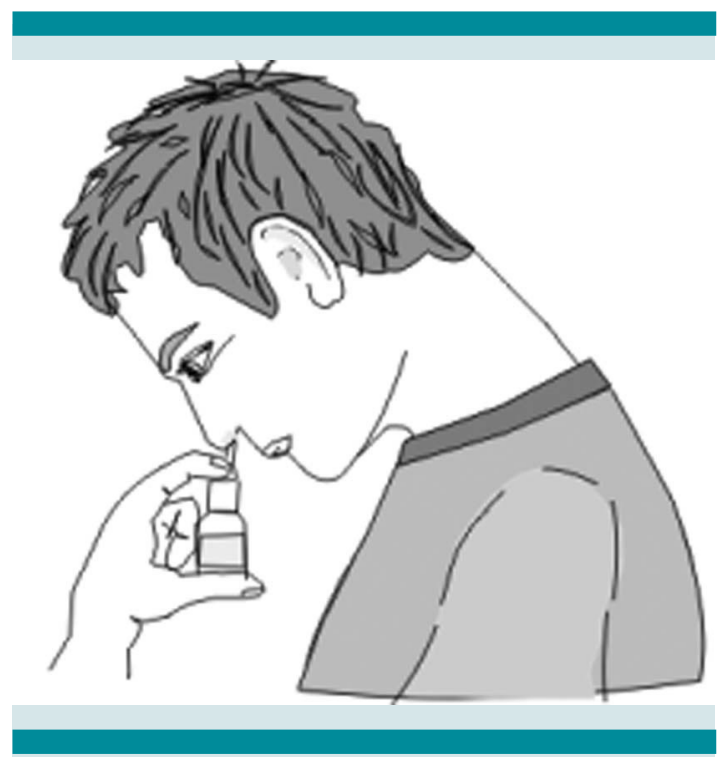

Figura 5. Técnica recomendada para administración de glucocorticoides nasales: 1) Colocar la barbilla hacia el pecho. 2) Ocluir una narina. 3) Colocar el dispositivo en posición recta en narina libre. 4) Disparar al mismo tiempo que se realiza inspiración.

después del baño se incrementa su absorción ya que la piel se encuentra mejor hidratada.

Los corticoesteroides tópicos cutáneos se clasifican de acuerdo a la potencia y ésta de acuerdo al tipo de glucocorticoides y al vehículo utilizado. Se recomienda aplicar utilizando el método de la unidad de la punta del dedo (0.5 gramos de crema/ungüento) para homogeneizar la dosis administrada y disminuir los efectos adversos locales (atrofia, telangiectasias, estrías, acné). Los glucocorticoides tópicos se absorben mejor en zonas de piel más delgada, por lo que se recomienda el uso de los glucocorticoides de menor potencia para la zona de la cara, cuello y pliegues y no se recomienda su aplicación alrededor de los ojos o de la boca ya que en pueden tener efecto en la mucosa circundante y ser absorbidos a circulación. Se recomienda iniciar el manejo con los de menor potencia y valorar duración o incremento de dosis de acuerdo a respuesta a tratamiento (Cuadro 4 y Figura 6).

\section{Glucocorticoides enterales}

Las alergias alimentarias comprenden un amplio grupo de enfermedades donde se produce una respuesta inflamatoria alérgica, desencadenada por un antígeno de la dieta. El tratamiento de elección es la dieta de exclusión del alimento, con lo que resuelve la sintomatología. Sin embargo, la ingesta accidental no es un evento 
Rodríguez-González M y Espinosa-Rosales F. Uso de glucocorticoides en alergia

Cuadro 4. Glucocorticoides tópicos (por orden de potencia relativa)
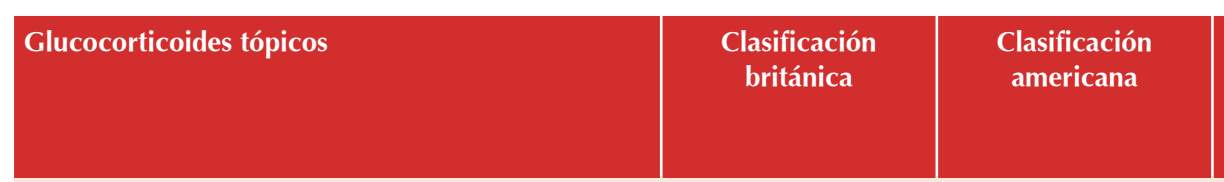

Preparación

c: crema

u: ungüento

I: loción

\begin{tabular}{|c|c|c|c|}
\hline Propionato de clobetasol $0.05 \%$ & 1 & I & $\mathrm{c}, \mathrm{u}$ \\
\hline Propionato de halobetasol $0.05 \%$ & I & 1 & $\mathrm{c}, \mathrm{u}$ \\
\hline Dipropionato de betametasona $0.05 \%$ & 1 & I & u \\
\hline Dipropionato de betametasona $0.05 \%$ & 1 & II & c \\
\hline Fluocinónido $0.05 \%$ & II & II & u \\
\hline Halcinónido $0.1 \%$ & II & II & c \\
\hline Furoato de mometasona $0.1 \%$ & II & II & $\mathrm{u}$ \\
\hline Dipropionato de betametasona $0.05 \%$ & II & III & $\mathrm{L}$ \\
\hline Propionato de fluticasona $0.005 \%$ & II & III & $\mathrm{u}$ \\
\hline Acetónido de Triamcinolona $0.1 \%$ & II & III & $\mathrm{u}$ \\
\hline Halometasona $0.05 \%$ & II & III & c \\
\hline Acetónico de fluocinolona $0.025 \%$ & II & IV & $\mathrm{u}$ \\
\hline Furoato de mometasona $0.1 \%$ & II & IV & c, I \\
\hline Butirato de hidrocortisona $0.1 \%$ & III & V & $\mathrm{C}$ \\
\hline Valerato de betametasona $0.1 \%$ & III & V & c \\
\hline Propionato de fluticasona $0.05 \%$ & III & V & c \\
\hline Acetónico de fluocinolona $0.01 \%$ & III & VI & $\mathrm{C}$ \\
\hline Desonide $0.05 \%$ & III & VI & $\mathrm{C}$ \\
\hline Dipropionato de alclometasona $0.05 \%$ & III & VI & $\mathrm{C}, \mathrm{u}$ \\
\hline Acetónido de Triamcinolona $0.025 \%$ & III & VI & $\mathrm{C}$ \\
\hline Hidrocortisona 1, 2.5\% & IV & VII & $c, \mathrm{u}, \mathrm{I}$ \\
\hline
\end{tabular}

Clasificación británica: muy potentes (grupo I), potentes (grupos II), de potencia moderada (grupo III) y de baja potencia (grupos IV).

Clasificación americana: superpotentes (grupo I), potentes (grupos II y III), de potencia intermedia (grupos IV y V) y de baja potencia (grupos VI y VII).

raro, y frecuentemente lleva a síntomas que requieren atención y tratamiento. Existen un grupo de enteropatías eosinofílicas donde se ha establecido la utilidad del uso de glucocorticoides sistémicos como locales (fluticasona o budesonida) como parte del tratamiento farmacológico. Cuadro 5.

Existen escenarios clínicos en los que en reacciones alérgicas graves está indicado el uso de glucocorticoides sistémicos, como parte del tratamiento o como pre-medicación.

\section{(Cuadro 6).}

Finalmente, la valoración por el especialista (alergólogo e inmunólogo pediatra) provee de otras dos herramientas importantes para identificar alérgeno responsable, indicar tratamiento modificador de la enfermedad y asignar pronóstico de acuerdo a fenotipo alérgico. 


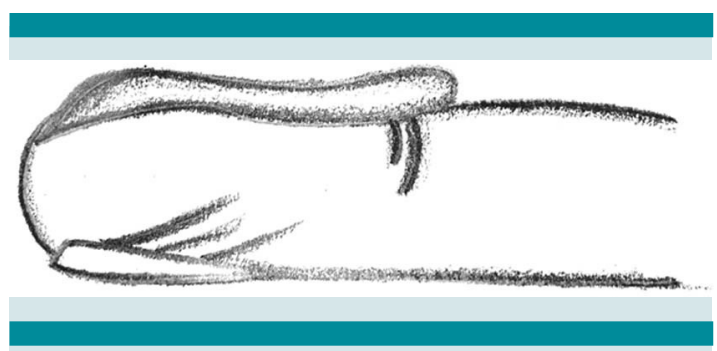

Figura 6. Método de la unidad de la punta del dedo que equivale a 0.5 gramos de crema/ungüento para la administración de esteroide tópico en piel.

\section{CONCLUSIONES}

Los glucocorticoides son una gran herramienta en el tratamiento farmacológico en las enfermedades alérgicas. Estar familiarizados con su uso y administración permite al pediatra indicarlos de forma segura y oportuna.

Cuadro 5. Glucocorticoides tópicos gastrointestinales

\begin{tabular}{l|c|c} 
Sustancia activa & \multicolumn{1}{|c|}{ Dosis } & \multicolumn{1}{c}{ Recomendaciones } \\
Fluticasona & $\begin{array}{l}88-440 \mathrm{mcg} / \text { día } \\
\text { (dividir en } 2 \text { dosis) }\end{array}$ & $\begin{array}{l}\text { Utilizar inhalador de dosis medida. Instruir al paciente para realizar el disparo con el } \\
\text { dispositivo en la boca y deglutir el medicamento. Minimizando el depósito pulmonar }\end{array}$ \\
Budesonida & $3 \mathrm{mg}$ & Utilizar cápsulas vía oral con capa entérica \\
& $<10$ años: $1 \mathrm{mg} /$ día & O \\
& &
\end{tabular}

Cuadro 6. Uso de glucocorticoides en reacciones alérgicas graves

\begin{tabular}{|c|c|c|}
\hline Ejemplo clínico & Indicación de uso & Comentario \\
\hline Anafilaxia & $\begin{array}{l}\text { El uso de glucocorticoides sistémicos } \\
\text { en anafilaxia se justifica únicamente } \\
\text { para prevenir o reducir la presencia de } \\
\text { la reacción bifásica: se estima que ésta } \\
\text { puede ocurrir hasta en } 20 \% \text { de los casos } \\
\text { y es una reacción tardía (horas a días) } \\
\text { mediada por activación celular }\end{array}$ & $\begin{array}{l}\text { En todos los casos la primera línea de tratamiento } \\
\text { es retirar al desencadenante, administrar adrenalina } \\
\text { intramuscular (dosis: } 0.01 \text { mgkg máx: 0,3-0.5 mg) y } \\
\text { mejorar el estado de hipoperfusión e hipoxia } \\
\text { Glucocorticoide sistémico: } \\
\text { metilprednisolona/prednisona/prednisolona } \\
\text { (1-2 mgkgdo) }\end{array}$ \\
\hline Alergias a medicamentos & $\begin{array}{l}\text { Uso de glucocorticoide en contexto de } \\
\text { anafilaxia }\end{array}$ & Ver anafilaxia \\
\hline Alergia a alimentos & $\begin{array}{l}\text { Uso de glucocorticoide en contexto de } \\
\text { anafilaxia }\end{array}$ & Ver anafilaxia \\
\hline $\begin{array}{l}\text { Alergia a veneno de in- } \\
\text { sectos (himenópteros) }\end{array}$ & $\begin{array}{l}\text { Uso de glucocorticoide en contexto de } \\
\text { anafilaxia }\end{array}$ & Ver anafilaxia \\
\hline $\begin{array}{l}\text { Antecedentes de reac- } \\
\text { ción a medios de con- } \\
\text { traste }\end{array}$ & $\begin{array}{l}\text { Cuando el paciente volverá a ser some- } \\
\text { tido al procedimiento radiológico y/o } \\
\text { quirúrgico y volverá a ser expuesto al } \\
\text { medio de contraste }\end{array}$ & $\begin{array}{l}\text { Glucocorticoide sistémico como pre-medicación: } \\
\text { metilprednisolona/prednisona/prednisolona }(0.5- \\
0.7 \text { mgkgdo) a las } 12 \text { y } 2 \text { horas previas ó a las } 13,7 \\
\text { y } 1 \text { hora previa al procedimiento }\end{array}$ \\
\hline $\begin{array}{l}\text { Antecedente de alergia } \\
\text { a látex }\end{array}$ & $\begin{array}{l}\text { Cuando el paciente será sometido a pro- } \\
\text { cedimiento médico/quirúrgico y volverá } \\
\text { a ser expuesto o a un ambiente donde } \\
\text { pueden existir partículas de látex }\end{array}$ & $\begin{array}{l}\text { Glucocorticoide sistémico como pre-medicación: } \\
\text { metilprednisolona/prednisona/prednisolona (0.5- } \\
0.7 \text { mgkgdo) cada } 8-12 \text { hrs por lo menos } 1 \text { día } \\
\text { previo al procedimiento }\end{array}$ \\
\hline
\end{tabular}


Rodríguez-González M y Espinosa-Rosales F. Uso de glucocorticoides en alergia

\section{LECTURAS RECOMENDADAS}

1. Tanno LK. Dissemination of definitions and concepts of allergic and hypersensitivity conditions. World Allergy Organization Journal. 2016;9:24.

2. Mallol J. The International Study of Asthma and Allergies in CHildhood (ISAAC) Phase Three: A global synthesis. Allergol Immunopahol. 2013;41(2):73-85.

3. Barnes PJ. Molecular mechanisms of corticosteroids in allergic diseases. Allergy. 2001;56:928-936.

4. Bacharier LB. Diagnosis and treatment of asthma in childhood: a PRACTALL consensus report. Allergy. 2008:63:5-34.

5. Global Strategy for Asthma Management and Prevention, Global Initiative for Asthma (GINA) 2016.

6. Weiler JM et al. Exercise-induced bronchoconstriction update-2016. J Allergy ClinImmunol 2016. In Press Corected Proof.
7. ARIA (Allergic Rhinitis and its Impact on Asthma) 2008 Update.

8. Sastre J, Mosges R. Local and systemic safety of intranasal corticosteroids. J Investig Allergol Clin Immunol. 2012;22:1-12.

9. Akdis CA. Diagnosis and treatment of atopic dermatitis in children and adults: European Academy of Allergology and Clinical Immunology/American Academy of Allergy, Asthma and Immunology/PRACTALL Consensus Report. J Allergy Clin Immunol. 2006;118:152-69.

10. Brazzini B, Pimpinelli N. New and established topical corticoste- roids in dermatology: clinical pharmacology and therapeutic use. Am J Clin Dermatol. 2002;3:47-58.

11. Ference JD, Last AR. Choosing topical corticosteroids. Am Fam Physician. 2009;79(2):135-140.

12. European Academy of Allergology and Clinical Immunology/ American Academy of Allergy. EAACI GUIDELINESFoodAllergy and Anaphylaxis. 2014.

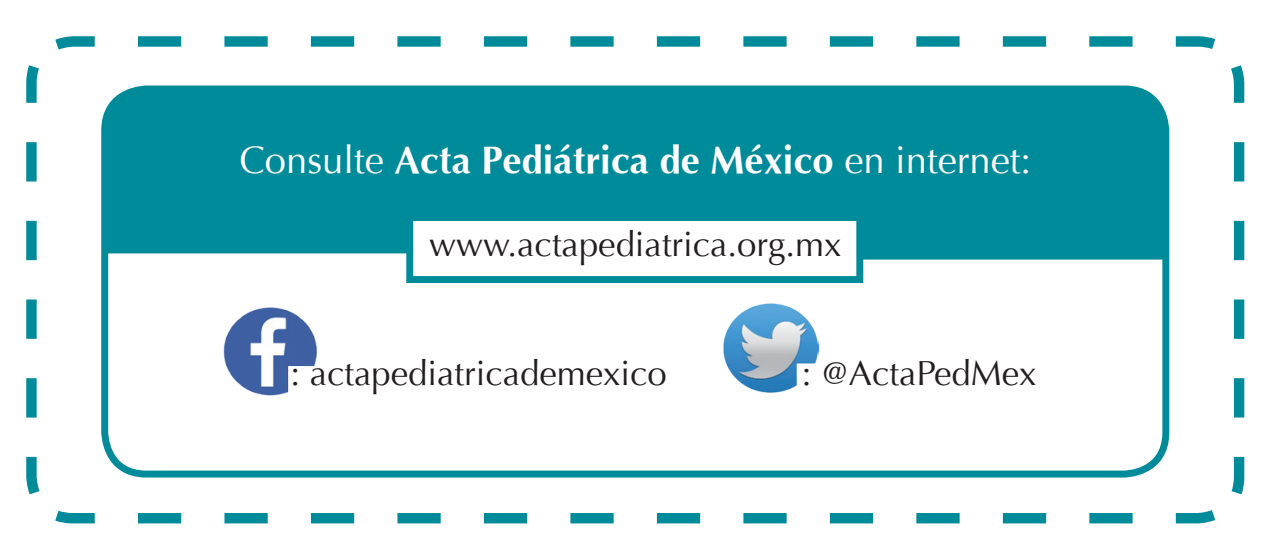

